\title{
ROLE OF bolA AND rpoS GENES IN BIOFILM FORMATION AND ADHERENCE PATTERN BY ESCHERICHIA COLI K-12 MG1655 ON POLYPROPYLENE, STAINLESS STEEL, AND SILICONE SURFACES
}

\author{
MOHD AdnAN ${ }^{1,3 *}$, ANA MARGARIDA SOUSA ${ }^{2}$, IDALINA MACHADO ${ }^{2}$, \\ Maria Olivia PEREIRA ${ }^{2}$, SAIF KHAN ${ }^{1}$, GLYN MORTON ${ }^{3}$ and SibTe HAdi ${ }^{3}$ \\ ${ }^{1}$ Department of Clinical Nutrition, College of Applied Medical Sciences, \\ University of Hail, Hail, Saudi Arabia \\ ${ }^{2}$ Institute for Biotechnology and Bioengineering, Centre of Biological Engineering, \\ University of Minho, Braga, Portugal \\ ${ }^{3}$ School of Forensic and Applied Sciences, University of Central Lancashire, Preston, UK
}

(Received: 10 February 2016; accepted: 25 August 2016)

Escherichia coli has developed sophisticated means to sense, respond, and adapt in stressed environment. It has served as a model organism for studies in molecular genetics and physiology since the 1960s. Stress response genes are induced whenever a cell needs to adapt and survive under unfavorable growth conditions. Two of the possible important genes are rpoS and bolA. The rpoS gene has been known as the alternative sigma $(\sigma)$ factor, which controls the expression of a large number of genes, which are involved in responses to various stress factors as well as transition to stationary phase from exponential form of growth. Morphogene bolA response to stressed environment leads to round morphology of $E$. coli cells, but little is known about its involvement in biofilms and its development or maintenance. This study has been undertaken to address the adherence pattern and formation of biofilms by E. coli on stainless steel, polypropylene, and silicone surfaces after $24 \mathrm{~h}$ of growth at $37^{\circ} \mathrm{C}$. Scanning electron microscopy was used for direct examination of the cell attachment and biofilm formation on various surfaces and it was found that, in the presence of bolA, E. coli cells were able to attach to the stainless steel and silicone very well. By contrast, polypropylene surface was not found to be attractive for $E$. coli cells. This indicates that bolA responded and can play a major role in the presence and absence of rpoS in cell attachment.

Keywords: E. coli, bolA, rpoS, biofilms, microbial adhesion

*Corresponding author; E-mails: drmohdadnan@gmail.com; mo.adnan@uoh.edu.sa 


\section{Introduction}

Bacteria commonly grow in surface-attached densely packed communities known as biofilms [1]. In other words, aggregates of cells embedded in a gluey matrix, the extracellular polymeric substance (EPS) [2]. Present view on biofilm formation is much more intricate, and is considered a well-controlled phenomenon $[3,4]$. Stress may be defined as any damaging factor that adversely affects the growth or survival of microorganisms [5]. Outcomes of stresses applied to microorganisms differ. In response to changes in their surroundings, bacteria have the ability to regulate the expression of genes that control their growth and physiology quickly [6]. In Escherichia coli, two of the possible important genes for biofilm growth are rpoS and bolA. RpoS is also called as a master regulator of general stress response [2]. Even though many studies have revealed the importance of rpoS and its regulated genes in planktonic cells under stress conditions, but less is known about the functions of rpoS in biofilms. In contrast, bolA, which is a morphogene in $E$. coli, is known for over expressing under stressed environments resulting in round morphology [7, 8]. It was foremost described to be implicated in adaptation to stationary form of growth. However, its function is still not completely understood and is not only confined to stationary phase, but its expression might also be induced by different forms of stresses such as heat shock, acidic stress, cold shock, etc., which results in the high-level expression of bolA mRNA and may lead to the formation of biofilms [9, 10]. E. coli seems to adhere and initiate biofilm development on specific and favorable surfaces, especially in response to specific environmental cues.

Both microbial adhesion and biofilms are of great importance from the industrial point of view, especially in the food industry, where it occurs on a high variety of surfaces in contact with food [11]. Bacteria are capable of sensing surfaces and adhesion occurs when microorganisms deposit and attach onto surfaces [12]. This attachment initiates a complex differentiation program, resulting in the synthesis of alginate and biofilm formation process. One study revealed that necessary and responsible genes for alginate production in Pseudomonas aeruginosa were shown to be upregulated within $15 \mathrm{~min}$ of contact with surface [13]. Various changes in gene regulation cause the biofilm cells to become phenotypically and metabolically different from their planktonic counterparts $[3,4,14]$. This difference has been persuasively shown in E. coli, Bacillus cereus, $P$. aeruginosa, and Pseudomonas putida. B. cereus a well-known food-poisoning organism [15] that produces biofilms on stainless steel in protein-rich media such as milk [16].

A multitude of studies exist where bacterial attachment to different surfaces has been studied with different bacterial species in different ionic strength, flow, and nutrient conditions. Recent example of one such study, which has assessed the 
occurrence of biofilm formation by human anaerobic periodontopathogens like Fusobacterium nucleatum, Eikenella corrodens, and Capnocytophaga spp. [17]. The adhesion of Bacillus spp. has also been extensively studied due to their deleterious impact in the dairy industry. Bacillus spores adhered as monolayers on many kinds of surfaces, hydrophobic spores of $B$. cereus being the most adhesive [18]. Various mechanisms exist by which different species of microorganisms are able to come into closer contact with a surface, attach firmly, promote cell-to-cell interactions, and grow as a biofilm [19]. The potential of bacteria to produce biofilms can be measured in the laboratory using microtiter plates. This method is simple and allows a large number of analyses to be carried out simultaneously. However, there are limitations to this technique in that commercially available substrata (microtiter plates) are limited to a number of different types of polystyrene. Therefore, the only method used in this study is microscopy. The most common method for the enumeration and morphological observation of microorganism on various surfaces is microscopy [20]. Scanning electron microscopy (SEM) is considered the most appropriate technique for evaluating the interaction of microorganisms in the biofilm matrix and was used for the investigation of biofilms on various substrates [20]. Involvement of rpoS and bolA genes in biofilm formation under various stress-induced conditions has been shown and studied previously [2]. However, whether these genes play an important role in the attachment of $E$. coli to specific surfaces or not is shown in this study.

\section{Materials and Methods}

Bacterial strains and growth conditions

E. coli K-12 MG1655 wild type (WT) and mutant strains $(\Delta)$ have been used in this study and were kindly provided by National Institute of Genetics, Japan. The WT strain was E. coli K-12 MG1655 and the mutants were E. coli $\mathrm{K}-12$ MG1655 rpoS mutant $(\Delta$ rpoS $)$ and $E$. coli $\mathrm{K}-12 \mathrm{MG1655}$ bolA mutant $(\Delta$ bolA $)$. Cells were grown in Luria-Bertani (LB) medium. Samples were taken at OD600 $=1.0$ and was considered as exponential growth phase, whereas OD600 $=2.2$ was considered to be stationary growth phase.

\section{Maintenance of bacterial cultures}

E. coli strains were maintained by sub-culturing them every 3-4 weeks onto LB agar (10 g tryptone, $5 \mathrm{~g}$ yeast extract, $5 \mathrm{~g}$ sodium chloride, and $10 \mathrm{~g}$ agar) purchased from Sigma-Aldrich Company Ltd., UK with a final $\mathrm{pH}$ value of 7.2. 
Cultures were streaked onto slopes of the agar and after overnight incubation at $37^{\circ} \mathrm{C}$, were stored at $4{ }^{\circ} \mathrm{C}$. LB agar is the preferred and recommended medium for molecular genetic studies with E. coli $\mathrm{K}-12$ strains and is used for routine cultivation. Stored cultures were recovered after approximately $18 \mathrm{~h}$ of incubation at $37{ }^{\circ} \mathrm{C}$ in $10 \mathrm{ml}$ of fresh medium. The cell densities of the cultures were determined by measuring the absorbance of $1 \mathrm{ml}$ sample using a Pharmacia LKB Novaspec II spectrophotometer at $600 \mathrm{~nm}$.

Cells were also stored/preserved for long term using a Mast Cryobank ${ }^{\mathrm{TM}}$ (Mast Group Ltd., UK). Mast Cryobank ${ }^{\mathrm{TM}}$ is based on a cryovial system comprising chemically treated ceramic beads covered with a special cryogenic preserving solution. It is the most convenient, reliable, and versatile system for storing and preserving bacteria over long periods at $-20{ }^{\circ} \mathrm{C}$ or $-70{ }^{\circ} \mathrm{C}$.

\section{Inoculum preparation}

A bacterial suspension was prepared by gently removing bacteria from the solid medium using a sterile nichrome loop to inoculate the bacteria into a $500 \mathrm{ml}$ flask containing $200 \mathrm{ml}$ of sterile nutrient medium. This bacterial suspension was incubated at $37{ }^{\circ} \mathrm{C}$ with agitation at $120 \mathrm{rpm}$ for $18 \mathrm{~h}$ to have bacteria in the exponential phase of growth.

\section{Glycogen assay (preliminary conformational test)}

$\operatorname{RpoS}^{+}$strains were screened for their ability to synthesize glycogen, as glycogen synthesis is under the direct control of $\operatorname{rpoS}$ to detect the $\operatorname{rpoS}$ mutant status [21]. Glycogen phenotypes of WT E. coli and $\Delta r p o S$ strains reveal a functional and non-functional status of $\operatorname{rpoS}$ sigma factor $\left(\sigma^{\mathrm{S}}\right)$. Colonies were grown on LB agar plates overnight at $37^{\circ} \mathrm{C}$ and then stored at $4{ }^{\circ} \mathrm{C}$ for another $24 \mathrm{~h}$ before they were flooded with concentrated iodine solution. Intracellular glycogen in colonies was stained with iodine resulting in two phenotypes: (1) dark brown colonies indicate glycogen-containing cells with functional $\sigma^{\mathrm{S}}$ (WT) and (2) white colonies indicate glycogen-deficient cells with non-functional $\sigma^{\mathrm{S}}(\Delta)$.

\section{Catalase activity}

Cultures were also tested qualitatively for catalase activity by applying $6 \%$ (wt/vol) $\mathrm{H}_{2} \mathrm{O}_{2}$ directly onto colonies on LB agar plates. Vigorous bubbling indicated WT rpoS activity and positive reaction to hydrogen peroxide. 
Biofilm formation assay: Crystal violet staining

A biofilm formation assay was performed using a microtiter plate. A volume of $20 \mu \mathrm{l}$ aliquots of an overnight culture with OD600 of 1.0 was inoculated into $200 \mu \mathrm{l}$ medium in a PVC microtiter plate. After $72 \mathrm{~h}$ incubation, the medium was removed from wells, which were then washed five times with sterile distilled water, and unattached cells were removed. Plates were air dried for $45 \mathrm{~min}$ and each well with attached cells were stained with $1 \%$ crystal violet solution in water for $45 \mathrm{~min}$. After staining, plates were washed five times with sterile distilled water. At this point, biofilms were visible as purple rings formed on the side of each well. The quantitative analysis of biofilm production was performed by adding $200 \mu \mathrm{l}$ of $95 \%$ ethanol to destain the wells. About $100 \mu \mathrm{l}$ from each well was transferred to a new microtiter plate, and the level (optical density) of the crystal violet present in the destaining solution was measured at $595 \mathrm{~nm}$.

\section{Experimental replication}

Data from all experiments, including control treatments for both the planktonic and biofilm phase, represent the averages of three or more independent experiments.

\section{SEM observations}

The SEM observation was made of at least 15 fields of each biofilm covered slides. Prior to the SEM observations, the biofilm samples were steadily dehydrated in an absolute ethanol series at 15 min each, in 10, 25, 40, 50, 70, 80, 90, and $100 \% \mathrm{v} / \mathrm{v}$ and then dried in a desiccator for 3 days. The samples were sputter coated with gold and examined with a Leica S360 SEM at 10-15 kV. The slides were not fixed because fixation action involves the use of chemicals that are likely to react with some of the components in the biological matrix, modifying the real biofilm structure, as has been documented by Azeredo et al. [22]. SEM observations were visualized through the acquisition of representative microphotographs.

\section{Results}

After $24 \mathrm{~h}$ of growth at $37^{\circ} \mathrm{C}$, adherence pattern of E. coli K-12 MG1655 on silicone, polypropylene, and stainless steel was studied. It was found that mutation in bolA did not support the cells to attach to polypropylene surface (image not shown). While in the presence of bolA, E. coli cells were somehow able to attach to the polypropylene surface. Very well attachment pattern was seen on stainless 


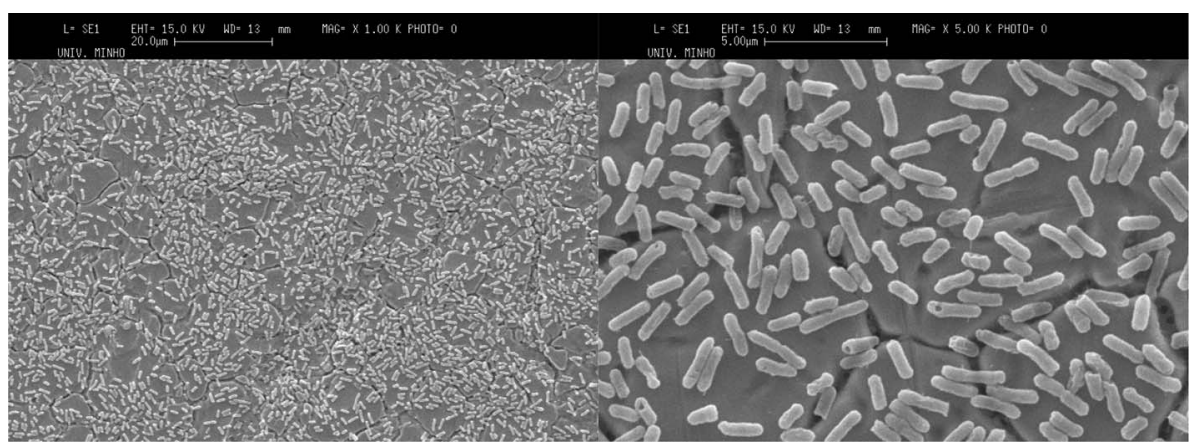

Figure 1. P1BACO 1/2: Scanning electron microphotograph of E. coli K-12 MG1655 $\left(\right.$ bolt $^{+} /$rpoS $\left.^{-}\right)$after $24 \mathrm{~h}$ at $37^{\circ} \mathrm{C}$ on stainless steel

steel surface in the presence of bolA (Figure 1). It can possibly form biofilms too under various environmental stress conditions on stainless steel. All three strains were able to attach to silicone surface very well (Figures 2-4). WT strain (i.e., in the presence of both $\operatorname{rpoS}$ and bolA genes) was found to form a thick biofilm mass on silicone surface, which shows that silicone is not a suitable surface for manufacturing and designing medical implants. In other words, it is the best surface for $E$. coli to attach and grow as biofilms without any stress conditions. This again proves the importance of $r p o S$ and bolA genes in E. coli attachment and biofilm formation. It also indicates that $\mathrm{bolA}$ responds and get regulated by some other genes in the absence of $r p o S$, which is also stated by Adnan et al. in bolA expression studies in planktonic and biofilm phase in both the presence and absence of $r p o S$ genes [2]. Polypropylene was not found to be the core surface for $E$. coli cells to attach and grow as biofilms (Figures 5 and 6). Some unusual result

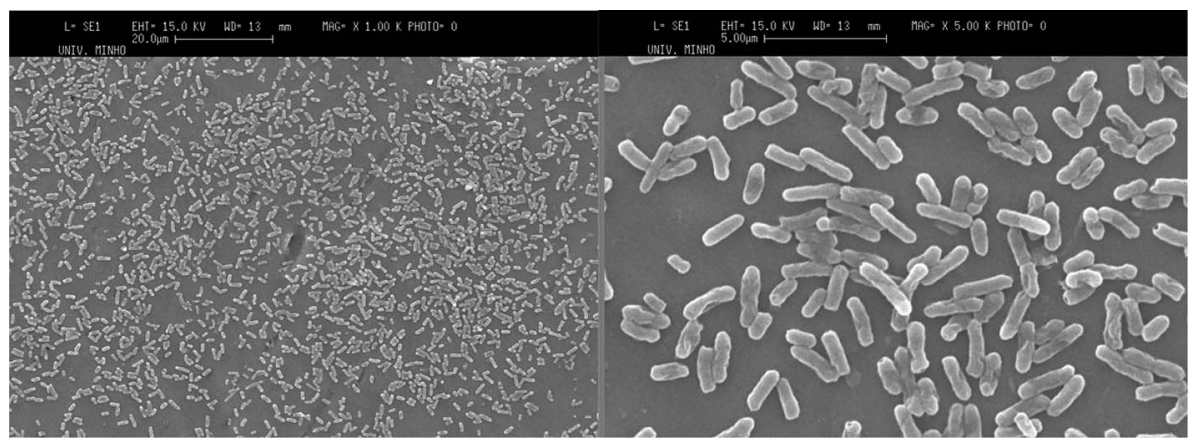

Figure 2. P1BSI 1/2: Scanning electron microphotograph of E. coli K-12 MG1655 $\left(\right.$ bolA $^{+} /$rpos $\left.^{-}\right)$after $24 \mathrm{~h}$ at $37^{\circ} \mathrm{C}$ on silicone 


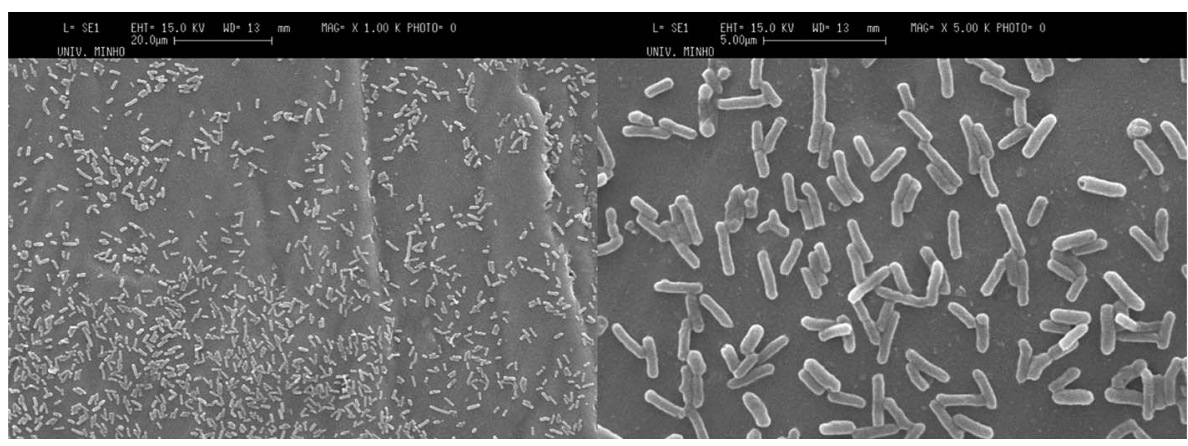

Figure 3. P1RSI $1 / 2$ : Scanning electron microphotograph of $E$. coli $\mathrm{K}-12 \mathrm{MG} 1655$ $\left(\right.$ bolA $\left.^{-} / r p o S^{\dagger}\right)$ after $24 \mathrm{~h}$ at $37^{\circ} \mathrm{C}$ on silicone

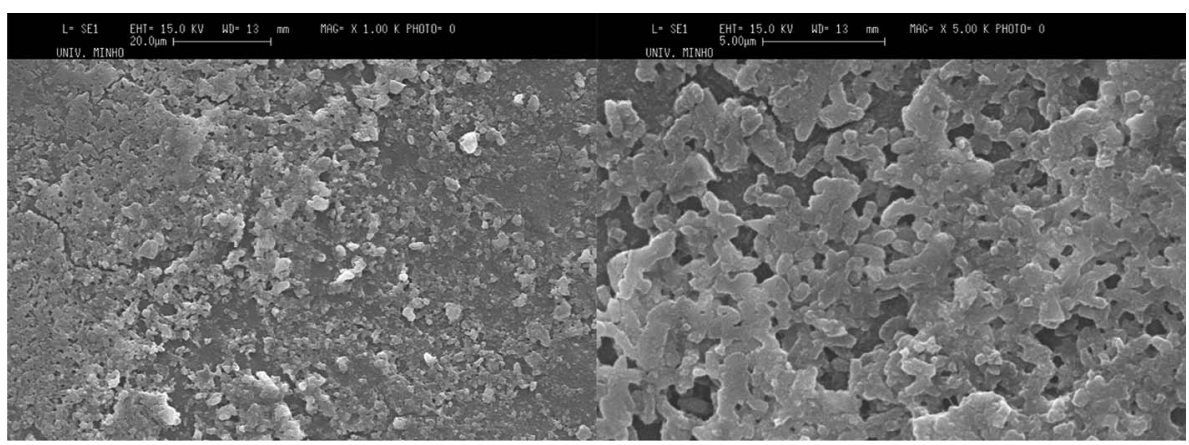

Figure 4. P1WTSI 1/2: Scanning electron microphotograph of E. coli K-12 MG1655 (WT) after $24 \mathrm{~h}$ at $37^{\circ} \mathrm{C}$ on silicone

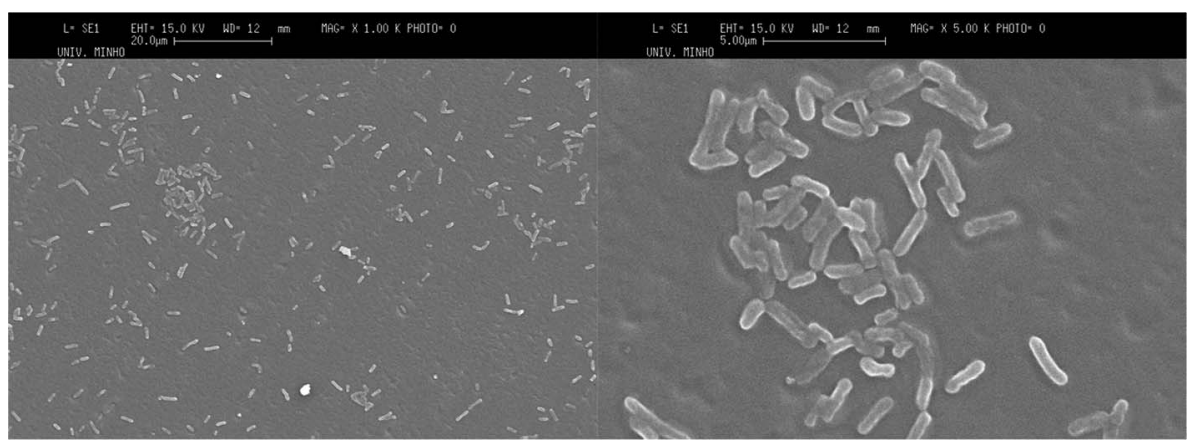

Figure 5. P1BPP 1/2: Scanning electron microphotograph of E. coli K-12 MG1655 $\left(\right.$ bol $\left.^{+} / r p o S^{-}\right)$after $24 \mathrm{~h}$ at $37^{\circ} \mathrm{C}$ on polypropylene 


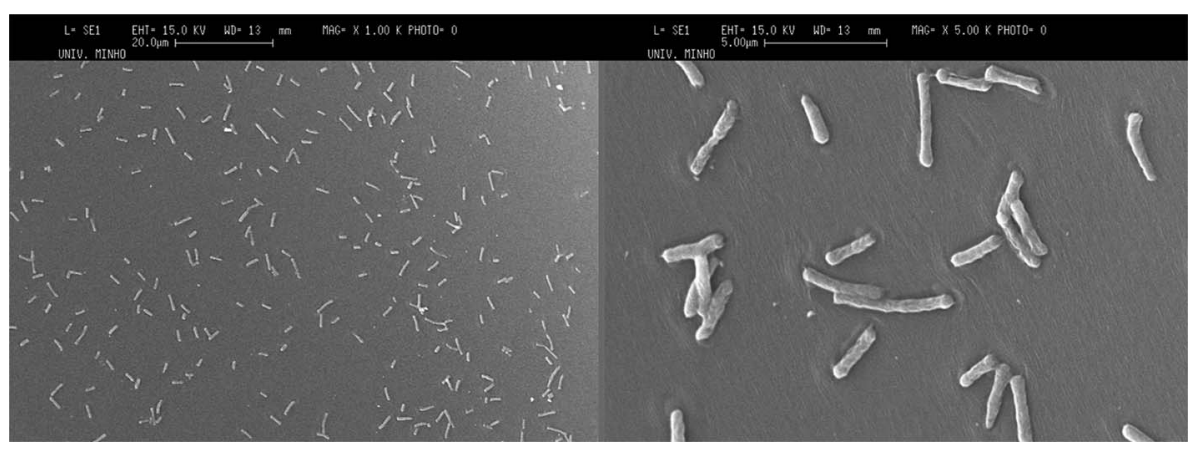

Figure 6. P1WTPP 1/2: Scanning electron microphotograph of E. coli K-12 MG1655 (WT) after $24 \mathrm{~h}$ at $37^{\circ} \mathrm{C}$ on polypropylene

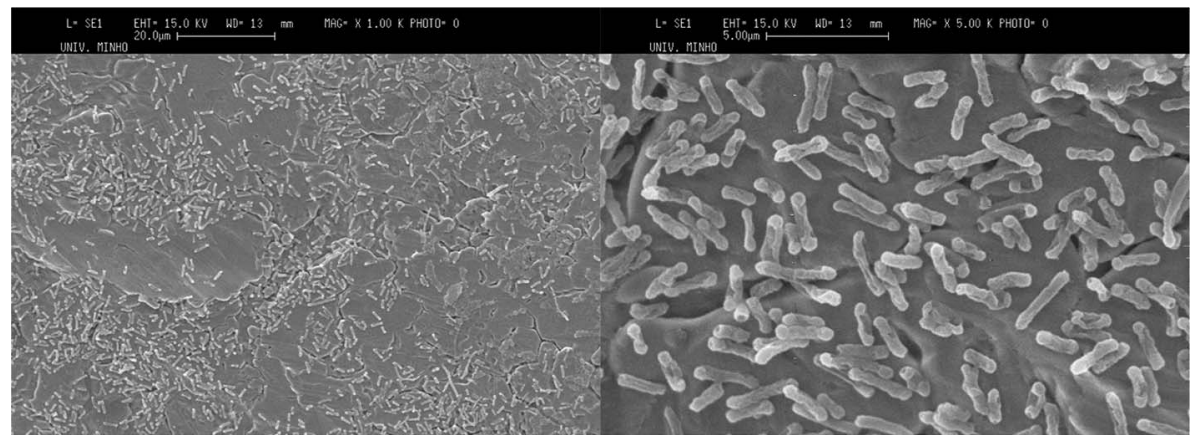

Figure 7. P1RACO 1/2: Scanning electron microphotograph of E. coli K-12 MG1655 $\left(\right.$ bolA $^{-} /$rpoS $\left.^{+}\right)$after $24 \mathrm{~h}$ at $37^{\circ} \mathrm{C}$ on stainless steel

was found in the case of WT strain of E. coli on stainless steel surface. No attachment was seen on the stainless steel by WT E. coli (image not shown). While bolA $A^{+} / r p o S^{-}$(the presence of bolA and the absence of $r p o S$ ) and $r p o S^{+} / b_{o l A}$ (the presence of $r p o S$ and the absence of $b o l A$ ) strains were able to attach very well on stainless steel surface. This point is under investigation at molecular level and can be studied further to come up with a justification that what makes $E$. coli to attach to the stainless steel with mutation in any one of these two genes but not with WT.

The conditions used in this study are listed in Table I. For the images presented, the following designations are used. For example, P1WTSI 1/2 should read as:

Condition: P1, plate 1

Strain: WT, wild type; B, bolA $A^{+} / r p o S^{-}$; and $\mathrm{R}, r p o S^{+} / b o l A^{-}$

Substrate: SI, silicone; ACO, stainless steel; and PP, polypropylene

1/2: Magnification under $1,000 \times(1)$ and $5,000 \times(2)$. 
Table I. Condition used in this study with the designated names and remarks

\begin{tabular}{|c|c|c|c|c|c|}
\hline Plate & Strain & Material & Name & Figure & Remark \\
\hline \multirow[t]{9}{*}{$24 \mathrm{~h}$ at $37^{\circ} \mathrm{C}$} & WT & Stainless steel & - & NA & Nothing visible \\
\hline & & Silicone & P1WTSI 1/2 & 4 & Thick biofilm \\
\hline & & Polypropylene & P1WTPP 1/2 & 6 & Less attachment \\
\hline & bolA $^{+} / r p o S^{-}$ & Stainless steel & P1BACO $1 / 2$ & 1 & Very well attached \\
\hline & & Silicone & P1BSI $1 / 2$ & 2 & Very well attached \\
\hline & & Polypropylene & P1BPP $1 / 2$ & 5 & Less attached \\
\hline & $\operatorname{rpoS}^{+} / \mathrm{bolA}^{-}$ & Stainless steel & P1RACO $1 / 2$ & 7 & Very well attached \\
\hline & & Silicone & P1RSI $1 / 2$ & 3 & Very well attached \\
\hline & & Polypropylene & - & NA & Nothing visible \\
\hline
\end{tabular}

\section{Discussion}

SEM allows the observation of bacteria-surface interaction and may be used as a semi-quantitative technique. It is almost impossible to quantify surface microorganisms, since they may be clustered and cells may be arranged in overlapping layers. In general, it was found that there were more cell attachments and biofilm formation on silicone surface compared to the stainless steel and polypropylene surfaces. This observation suggests the ability of the $E$. coli cells to adhere to silicone is greater than their ability to adhere to stainless steel or polypropylene surface. Our study is also indicating the role of rpoS and bolA in cell attachment and importance of silicone and stainless steel as the optimal surface for most bacterial biofilms to attach and develop without any induced stress conditions. The extent of biofilm accumulation on surfaces is controlled by the amount of nutrients available for cell replication and EPS production [23, 24]. A rich nutrient environment provides an ideal environment for bacteria to adhere, thus triggering biofilm formation through the secretion of EPS [25]. Bacteria do not form biofilms where the nutrients are lacking. They will leave the environment and revert back to the free-swimming life style [26]. Similarly, E.coli cells reach the highest population density when the nutrients in the environment are optimal. This study can be further experimented up to $72 \mathrm{~h}$ with reduced nutrient availability, and various other induced stress conditions. Variation in cell morphology under these environments and surfaces can also be studied. The SEM evidence provided by this study shows the attachment of $E$. coli on various substrates. SEM was also found to be a powerful tool in successfully investigating the cell density and interaction of biofilms on various substrates in the presence and absence of rpoS and bolA genes. Attachment pattern of E. coli on various substrates can be considered in various ways and might be used productively for industrial, environmental, and medical purposes. 


\section{Acknowledgements}

The authors would like to thank the University of Hail for their kind support and they would also like to thank all the staff members and students of IBB, Centre of Biological Engineering, University of Minho for lending their expertise and assistance with SEM.

\section{Conflict of Interest}

The authors declare that they have no conflict of interest.

\section{References}

1. Adnan, M., Morton, G., Singh, J., Hadi, S.: Contribution of $r p o S$ and bolA genes in biofilm formation in Escherichia coli K-12 MG1655. Mol Cell Biochem 342, 207-213 (2010).

2. Adnan, M., Morton, G., Hadi, S.: Analysis of $r p o S$ and bolA gene expression under various stress-induced environments in planktonic and biofilm phase using $2^{-\Delta \Delta C T}$ method. Mol Cell Biochem 357, 275-282 (2011).

3. Kuchma, S. L., O'Toole, G. A.: Surface-induced and biofilm-induced changes in gene expression. Curr Opin Biotechnol 11, 429-433 (2000).

4. Stoodley, P., Sauer, K., Davies, D. G., Costerton, J. W.: Biofilms as complex differentiated communities. Annu Rev Microbiol 56, 187-209 (2002).

5. Vorob'eva, L. I.: Stressors, stress reactions, and survival of bacteria: A review. Appl Biochem Microbiol 40, 217-224 (2004).

6. Adnan, M., Machado, I., Sousa, A. M., Pereira, M. O., Morton, G., Hadi, S.: Involvement of bolA and rpoS genes in oxygen uptake (respirometry) by E. coli K-12 MG1655 under various stress conditions. Asian J Microbiol Biotechnol Environ Sci 15, 19-24 (2013).

7. Adnan, M., Pereira, M. O., Machado, I., Morton, G., Hadi, S.: Morphogene BolA: Its role in biofilm formation and respiration of E. coli K-12 MG1655. Clin Microbiol Infect 16, S571 (2010).

8. Santos, J. M., Freire, P., Vicente, M., Arraiano, C. M.: The stationary-phase morphogene bolA from Escherichia coli is induced by stress during early stages of growth. Mol Microbiol 32, 789-798 (1999).

9. Khona, D. K., Dongre, S. S., Arraiano, C. M., D'souza, J. S.: A BolA-like morphogene from the alga Chlamydomonas reinhardtii changes morphology and induces biofilm formation in Escherichia coli. FEMS Microbiol Lett 339, 39-47 (2013).

10. Vieira, H. L. A., Freire, P., Arraiano, C. M.: Effect of Escherichia coli morphogene bolA on biofilms. Appl Environ Microbiol 70, 5682-5684 (2004).

11. De Oliveira, M. M. M., Brugnera, D. F., Alves, E., Piccoli, R. H.: Biofilm formation by Listeria monocytogenes on stainless steel surface and biotransfer potential. Braz J Microbiol 41, 97-106 (2010).

12. O’Toole, G. A., Stewart, P. S.: Biofilms strike back. Nat Biotech 23, 1378-1379 (2005). 
13. Dunne, W. M.: Bacterial adhesion: Seen any good biofilms lately? Clin Microbiol Rev 15, 155-166 (2002).

14. Watnick, P. I., Kolter, R.: Steps in the development of a Vibrio cholerae El Tor biofilm. Mol Microbiol 34, 586-595 (1999).

15. Granum, P. E., Lund, T.: Bacillus cereus and its food poisoning toxins. FEMS Microbiol Lett 157, 223-228 (1997).

16. Kim, H., Ryu, J. H., Beuchat, L. R.: Attachment of and biofilm formation by Enterobacter sakazakii on stainless steel and enteral feeding tubes. Appl Environ Microbiol 72, 5846-5856 (2006).

17. Mártha, K., Lőrinczi, L., Bică, C., Gyergyay, R., Petcu, B., Lazăr, L.: Assessment of periodontopathogens in subgingival biofilm of banded and bonded molars in early phase of fixed orthodontic treatment. Acta Microbiol Immunol Hung 63, 103-113 (2016).

18. Husmark, U., Runner, U.: Adhesion of Bacillus cereus spores to different solid surfaces: Cleaned or conditioned with various food agents. Biofouling 7, 57-65 (1993).

19. Simoes, L. C., Simoes, M., Vieira, M. J.: Biofilm Interactions between distinct bacterial genera isolated from drinking water. Appl Environ Microbiol 2007, 6192-6200 (2007).

20. Abed, S. E., Ibnsouda, S. K., Latrache, H., Hamadi, F.: Scanning electron microscopy (SEM) and environmental SEM: Suitable tools for study of adhesion stage and biofilm formation. In Scanning Electron Microscopy. InTech, Croatia, 2012, pp. 717-730.

21. Hengge-Aronis, R., Fischer, D.: Identification and molecular analysis of $g \lg S$, a novel growth-phase-regulated and, rpoS-dependent gene involved in glycogen synthesis in Escherichia coli. Mol Microbiol 6, 1877-1886 (1992).

22. Azeredo, J., Lazarova, V., Oliveira, R.: Methods to extract the exopolymeric matrix from biofilms: A comparative study. Water Sci Technol 39, 243-250 (1999).

23. Bester, E., Wolfaardt, G. M., Aznaveh, N. B., Greener, J.: Biofilms' role in planktonic cell proliferation. Int J Mol Sci 14, 21965-21982 (2013).

24. Donlan, R. M.: Biofilms: Microbial life on surfaces. Emerg Infect Dis 8, 881-890 (2002).

25. Costerton, J. W.: Overview of microbial biofilms. J Ind Microbiol Biotechnol 15, 137-140 (1995).

26. Williams, H. N., Kelley, J. I., Baer, M. L., Turng, B. F.: The association of bdellovibrios with surfaces in the aquatic environment. Can J Microbiol 41, 1142-1147 (1995). 